\title{
BEYOND THE PORTAL
}

A Study of the Tangible and Intangible Rituals within Sacred Spaces

\author{
CYRUS QURESHI ${ }^{1}$, TANE JACOB MOLETA ${ }^{2}$ and \\ MARC AUREL SCHNABEL ${ }^{3}$ \\ 1,2,3 Victoria University of Wellington \\ ${ }^{1}$ cyrusqureshi@gmail.com ${ }^{2,3}\{$ Tane.Moleta \\ MarcAurel.Schnabel\}@vuw.ac.nz
}

\begin{abstract}
In its ambitions, the paper aims to propose a proof of concept for a Virtual, Augmented and Mixed (VAM) environment that digitally overlays a multifaith space in order to optimize their use, essentially transforming itself to the spiritual needs of the user. In order to do so, a mixed reality experience was developed by investigating and interpreting both the tangible and intangible rituals of prayer. By incorporating an immersive experience, the project promotes the idea of a multifaith space that moves beyond the notion of an "empty white room (Crompton, 2013, p.487)". To develop an immersive experience that caters to people of all religions or no religion is beyond the scope of this project. Hence, by creating a VAM environment for users of the Muslim faith the project may be able to support design ideologies for others, furthering research in this field.
\end{abstract}

Keywords. Tangible and Intangible Rituals; Multifaith Space; Mixed Reality; Digital Mosque.

\section{Introduction}

Through the passage of time, places of faith have assumed certain architectural forms. Progressively, they have increasingly become adorned by symbols that are recognizable by all. For various communities, religious symbols invoke peace, a sense of solidarity and spiritual awakening. Navneet Kaur states, "Symbolism for any community or group of people is a direct expression of their beliefs, ideas, fears \& celebrations" (Kaur, 2012, p.05). However, this rich collection of texts, artworks, garments, artifacts, and practices that associate with a specific religion also distinguish one people's group from another. Due to the socio-political climate of today and the ever-changing demographics of our world, religion and the symbols associated with it are more relevant than ever before. Even while living in multicultural cities we seem to be more ignorant than ever before on the various cultures and religions that have shaped our communities. This ignorance leads to fear and apprehension, disrupting the social fabric within the community.

In "Living with Difference: How to Build Community in a Divided World", the authors introduce us to the idea of "emergent spaces (Seligman, Wasserfall

Intelligent \& Informed, Proceedings of the $24^{\text {th }}$ International Conference of the Association for Computer-Aided Architectural Design Research in Asia (CAADRIA) 2019, Volume 1, 525-534. (C) 2019 and published by the Association for Computer-Aided Architectural Design Research in Asia (CAADRIA), Hong Kong. 
and Montgomery, 2015, p. 35)", that manifest once a community accepts its differences and is able to reframe collectively its goals and desires. An example of such a space is that of a multifaith space, a platform that aims to accommodate all members of a community regardless of their religious or spiritual beliefs. Theoretically, the notion of a multifaith space is exciting as one begins to imagine how members of a community can look towards a common architectural body to fulfill their spiritual and religious needs. However, in its current conception, the multifaith space is limited to room scale spaces within select fragments of the urban infrastructure such as airports, shopping malls, or hospitals etc. In most scenarios, the rooms are treated as purely functional entities to the point where the experience within the space becomes monotonous. They are a space meant for everyone yet, troublingly, spaces where no one wishes or is able to belong. Contrarily, religious architecture, whether it may be a church, mosque or temple, has been successfully translated into the collective memory of larger society, but within multifaith spaces, our focus has been on neutralization and in the process voided the space of any rich phenomenological experience.

As a result, this research looks towards advanced technologies such as Virtual, Augmented and Mixed Reality (VAM) as a possible toolset for evolving the inhabitable narratives within multifaith spaces. By doing so, the research attempts to activate the space in order to create a rich experience that captures the imagination and furthers the role of multifaith spaces within communities. The opportunities presented by mixed reality technologies enable the designer to rethink how a space functions and is experienced. Not limited by the permanence of physical architecture, VAM spaces can be generated in ways that are transformable, responsive and adaptable, which this thesis proposes is fundamental to the spiritual needs of every user. Hereby, this research proposes a proof of concept for a VAM environment that digitally overlays on an existing multifaith space in order to optimize its use. In order to do so, further research needs to be conducted in the framework of a specific religion. In this case, Islam was defined as the principal faith of study. This allowed an interrogation of Mosque architecture to understand how users of the Muslim faith can be accommodated within such a space.

By focusing on Islam and the evolution of Mosque architecture, this research gains to understand what is today deemed 'Islamic Architecture. Furthermore, an investigation and interpretation of both the tangible and intangible rituals involved in Islamic prayer helped to determine the ability of VAM to evolve an immersive experience. By incorporating an immersive experience, the project promotes the idea of a multifaith space that moves beyond the notion of an "empty white room (Crompton, 2013, p.487)". Hence, by creating an MR environment for users of the Muslim faith the project may be able to contribute design concepts and methods for others, furthering research in this field.

\subsection{AIMS AND OBJECTIVES}

The aim of this research is to theorize an immersive experience for Muslim users as part of a larger notion of a mixed reality multifaith space.

The objectives will (1) Investigate Spaces for Prayer within selected tertiary 
educational institutions in Wellington in order to establish parameters for their optimization, (2) Study current Mixed Reality theories and technologies in order to build a methodology that incorporates MR design tools within traditional architecture frameworks, and (3) Apply this research to designing an environment that supports the notion of an Adaptive Multifaith Space.

\section{Research Topics}

\subsection{SACRED SPACE}

The topic of Sacred Space aims to be understood through two perspectives; primarily, through the lens of history, evolution in design and religion, in order to do so, a study of Mosque Architecture may provide better insight. Secondly, the architectural and conceptual study of a more contemporary notion of a sacred space, that is, the Multifaith Space.

\subsubsection{Mosque Architecture}

For practicing Muslims, Salah/prayer is essential to daily life as they perform it five times a day. The daily prayers are considered to be an act of worship and a conversation between the believer and Allah, they can be performed either in a commune or in isolation. As a result, the Mosque in Islam can be considered as any 'bounded space (Longhurst, 2016, p.49)' that houses prayer. The only requirements assigned for this practice are that one should cleanse (Wudu) themselves before prayer and the selected place for worship should be as clean as possible. As a result, Muslims perform prayer with ease as they go on about their daily lives. The mosque as a place for worship retains both ephemeral qualities and those of permanence, the mosque can be a single prayer mat and at the same time, the size of a city block. In New Mosques: Design and Vision, Holger Kleine states, "The Quran neither prohibits nor encourages the design of monumental buildings for the worship of God or other artistic expression" (Kleine, 2014, p.11) Limited by no restrictions, the architectural notion of a mosque is forever evolving, adapting and being reimagined according to regional and cultural shifts that came with the spread of Islam. The study of its history and evolution will help to clarify the concepts behind its design and role within society. Furthermore, it will provide a greater understanding of the future of mosque architecture, within a digital society.

\subsubsection{Multifaith Space}

Diversity enables change and by embracing it we open ourselves to spiritual and religious pluralism. Although not a historically recent concept, the notion of spiritual pluralism has existed in some form, actively or passively, within communities across the globe. Today, this idea of a shared space for religious activities has materialized architecturally as a Multifaith Space. Professor Andrew Crompton explains this as, "A new kind of sacred environment in which anyone can pray whatever their religion...The most common and characteristic type is a windowless white room with a few religious texts on a shelf and the paraphernalia of religion, when not actually in use, kept out of sight in boxes (Crompton, p.474, 
2013)". The challenges that come with the designing of such culturally rich spaces are plenty, however, the opportunity to tackle the theoretical and architectural problems of religious spaces are tenfold. For instance, multifaith spaces offer an alternative to separate prayer rooms for distinct religious groups. Considering the limited amount of space available within public buildings this helps to resolve a crucial issue faced by designers and planners.

\subsection{MIXED REALITY}

Architecture has often been the center stage for social interactions but today, these interactions have moved beyond just the built environment and onto digital platforms. Considering the new paradigm shift, religion and the practices involved must also adapt and evolve. Within academic discourses, we begin to see the generation of new ideas and concepts. In his paper, 'The Digital Mosque: A New Paradigm in Mosque Design', Imdat As, considers technology as a platform by which to advance our current understanding of a mosque and the various Islamic practices involved. He introduces the idea of a "convergent mosque (Imdat As, 2006, p.61)", an online mosque paradigm converging the virtual and physical spaces. Furthermore, 'Whispering Walls: Cultural augmentation with augmented reality at a range of scales', by Krishna Duddumpudi aims to translate traditional handicraft ideologies to augmented reality in order reconnect individuals to the Hindu temples of South India. By exploring the notion of 'info-tectonic' details (Duddumpudi, 2013, p.507) and the digital medium, the project allows users to engage, learn and document their culture that responds to the needs of contemporary society.

\subsection{TANGIBLE AND INTANGIBLE RITUALS}

Religious spaces evoke certain spiritual experiences through an amalgamation of tangible and intangible rituals that aim to stimulate the human mind and body. The rituals become the primary driver for inhabitable narratives within sacred spaces influencing the architecture and the phenomenological experience within Tangibility in the context of rituals can be understood as any practice that can be perceptible by touch, for instance the ritualized cleansing of oneself with water before entering Sikh gurdwaras and Islamic mosques or to heal oneself with the smoke of burnt incense as practiced in some Buddhist and Shinto shrines and temples. While intangibility moves beyond, attempting to awaken the mind and spirit through ritualized acts of prayer, recitation and a plethora of music and soundscapes; for instance, listening to the choir at a Church or chanting of mantras at Hindu temples. In order to house these ritualized practices, architecture embraces the notion of tangible and intangible rituals by forming spaces that support the function and create an environment around the space to enhance the human experience.

\section{Literature}

Mass migration is a reality of our world today, creating mixed societies that are transforming our urban fabric. The impact of migration can be seen across the 
continents but no where is it more evident than in Western cities. For decades now, people have been migrating to Western shores either as refugees fleeing war/famine/persecution or as immigrants seeking employment and education for a better future. With migration comes the addition of distinct cultures, traditions and religions that attempts to fuse so naturally with the customs of the host nation

With the ever-changing demographics of our world today, more mosques are being built in the West, but little has changed in terms of the design considering the new context. In his paper, Professor Longhurst questions the notion of the 'Islamic Style' or 'Islamic Architecture'. He highlights, "In the history of mosque architecture there are Ottoman-Turkish styles, Arabic and Persian styles which may or may not be traditional, or a style after the Prophet's house - the Arab-plan, hypostyle, four-iwan, or centrally planned styles, etc., but no "Islamic style," because the term "Islamic" cannot be said of architectural style without betraying, an ignorance of Islam's inclusivity, a religion as a totality of parts, flexible and variant in architecture (Longhurst, 2016, p.51)." Professor Longhurst emphasis the importance of a Mosque typology that moves beyond culture and time to a more universal concept of Islam as it is today represented by 1.6 billion Muslims from every region of the world.

In his paper, "The Architecture of Multifaith Spaces: God Leaves the Building", Professor Andrew Crompton introduces us to the several design problems involved in the architecture of multifaith spaces. Considered as sacred spaces, the multifaith space intends to assist in the user's spiritual needs. Spaces such as these cannot resemble any place of religion, express symbols or styles that may make it evocative. In the paper, Andrew discusses the significance of an 'empty white room' and draws comparisons to art movements that changed how the world perceived art. He states, "The blank paintings did not destroy art, rather they were a motor of its evolution, part of the dematerialization of art that has continued to this day (Crompton, 2013, p.493)." Furthermore, in his research, he categorizes the multifaith space distinctively as inclusive or exclusive of physical symbols. By being physically inclusive, space attempts to incorporate the numerous paraphernalia associated with each faith. According to Crompton, the architectural solutions can be "theatrical, expensive or potentially comic". On the other hand, by being physically exclusive, space seeks to breaks away from the past in an attempt to provide designers with a clean slate.

However, by simply whitewashing the multifaith space have we been too quick to discard the rich cultural and historical past of religious spaces and in the process, refused to acknowledge the sentimental value the paraphernalia may have for numerous users. Instead, by introducing current mixed reality technologies into the equation we may achieve a space that embraces both the inclusive and exclusive taking elements from each space. Mixed realities provide us with the opportunity to intersect the physical multifaith room with digital religious elements in an attempt to create a multifaith space that adapts to the user's requirements. By doing so, users gain the freedom to inhabit a space that caters to their needs without being physically intrusive into anyone else's beliefs. Hereby, acknowledging the rich history and cultural value instilled in religious spaces but also acting as a catalyst for the evolution of design. 


\section{Methodology}

The research methodology begins by asking crucial questions targeting the politics of symbols within architecture in order to understand how it affects us as a highly globalised society. Investigation of literature and case studies helps to build the core ideas on how to pursue this thesis. Furthermore, primary research in terms of site visits and discussions with experts and individuals provides direction. As the design aims to create an immersive environment, various tools and techniques needed to be studied, learned, tested and implemented. All of these processes supported the formulation of architectural principles that in the end forms a design that acts as a proof of concept for an adaptive multifaith space.

Preliminary research involved the investigation of spaces dedicated to the spiritual needs of occupants within tertiary education buildings of Wellington. These include Victoria University of Wellington (Kelburn, Te Aro and Pipitea Campuses), University of Otago (Wellington Campus) and Massey University (Wellington Campus).

It was found, all university campuses provide two distinct spaces that cater to the spiritual/religious needs of its occupants. Firstly, a Chaplaincy run by representatives of the Church and secondly, an Islamic prayer room for Muslim occupants to offer their 5 times daily prayers. The Chaplaincy offers a range of services including spiritual guidance and a support network. As a result, within these university campuses we find that a significant group of inhabitants are neglected simply because they do not adhere to either religious group. To conclude, diverse universities such as these must consider the spiritual needs of all its students and staff. In order to do so, by incorporating multifaith spaces the university may be able to facilitate everyone.

Further research involved the investigation of the Muslim prayer rooms in order study how they facilitate Muslims in performing their Islamic duties. The pre-existing prayer rooms have been refurbished with some major to minor interior design altercations ranging from the addition of a wudu/cleansing fountain to the placement of paraphernalia such as prayer mats, garments and religious texts. The entities within each room formed a list of quantitative (the paraphernalia categorized according to its function or purpose) and qualitative (the interpretation of the paraphernalia from a tangible physical object to an intangible virtual concept) data. The analysis of this data formed the foundations for the design of the immersive environment. For instance, the physical prayer mat signifies not only the specific place upon which to pray but also orients the person towards the Holy Kaaba (the House of God) in Mecca, Saudi Arabia, this is the direction in which Muslims are required to pray five times a day. This physical object can be reinterpreted within a virtual context as an abstract entity that does not need to be a permanent feature of the room. On the other hand, the wudu/cleansing fountain are more difficult to interpret and require investigation of the Quran in order to conceptualize it virtually. Wudu/cleansing, is the cleansing of the mind and body prior to prayer. This is a very tangible act and requires one to physically wash themselves from head to toe with water. However, a study of the Quran revealed the notion of Tayammum/dry washing. 
"O Believers! When you prepare for prayers, wash your faces and your hands up to the elbows, and wipe your heads, and your feet to the ankles ... and [if you] do not find water then betake yourselves to clean earth and wipe your faces and your hands with it." (Holy Qur'an: Chapter 5, Verse 6)

This verse from the Quran reveals that wudu/cleansing is more than just washing the body with water, it is through the enactment that a Muslim mentally and physically prepares themselves for the spiritual act of worship. As a result, through augmented-virtuality the Muslims can perform Virtual Tayammum the augmentation of the physical act of performing wudu/cleansing with digital elements that can be considered as an abstracted representation of water. Through this process of data analysis, the research was able to develop a conceptual framework for designing the immersive experience. The conceptual framework includes four key events to be designed in order to present a proof of concept for a MR experience for users of the Muslim faith. These events include; (1) Entering the physical space within which worship is to take place and upon which the digital elements are to be overlayed, (2) Listening to the adhan/call to prayer that signifies the time for prayer and initiates the mental preparation for worship (3) Performing Virtual Tayammum - cleansing of the mind and body prior to worship, and, (4) Performing Salah/prayer - the act of worship.

\subsection{INSTRUMENTS OF DESIGN}

Designing for MR environments requires venturing out in search for architecturally non-traditional instruments of design. The conceptual framework stated above aims to take us on a journey across the spectrum of mixed realities (real environment - augmented reality - augmented virtuality - virtual reality). As a result, within the methodology various tools and techniques had to be studied, tested and implemented in order to develop the MR experience.

1) Photogrammetry: The process involved a trial and error method for photographing the prayer room along with the exploration of various photogrammetry software in order to capture the room accurately. The software tested include Reality Capture, 3DF Zephyr, ReCap Photo and Agisoft Photoscan.

2) Digital Design Tools: Rhino3D (computer-aided design, CAD) and Grasshopper3D (a visual programming language) were used to design various geometry and game objects for interaction within the immersive experience.

3) Game Engine: Unity3D (real-time virtual engine) along with Monodevelop (a platform for writing code) was used to create the virtual environment.

4) Motion Capture: OptiTrack - Motive was used to capture the various movements of the human body involved in performing wudu/cleansing and salah/prayer. The study of ergonomics is crucial to any architectural project. Even more so, when the aim of the design is to create an immersive experience that highlights the various religious activities performed by Muslims. By capturing, visualizing and interpreting the various movements the project aims to present a direct link between the body and the digital space.

5) Mixed Reality Simulation: Experiencing the end design moves beyond architectural drawings, experientials and 3-dimensional models towards 
immersing oneself within the architectural environment through the use of MR headsets. Ideally, the user would walk into a physical room wearing an AR headset such as the Microsoft's Hololens and from there digital elements would overlay the room as the user transitions from one key event to another. Unfortunately due to the limitations of current AR headsets in providing a holistic immersive experience this technique was not implemented. Instead, for the purpose of grounding the proof of concept, the MR Mosque is to be experienced via the VR based HTC Vive headset. HTC Vive headset uses room scale tracking technology to allow the user to experience a virtual environment within a 3D space.

6) Hand Tracking Technology (Future Research): Leap Motion is sensory hardware device that enables hand and finger motion tracking within MR environments. Future research aims to test hand tracking technology in order to develop a truly immersive augmented-virtuality experience as part of the wudu/cleansing and salah/prayer events.

\section{Design}

\subsection{SEQUENCE OF EVENTS}

The conceptual framework proposes four key events to be designed in order to present a proof of concept for an MR experience for users of the Muslim faith.

(1) Entering the physical space within which worship is to take place and upon which the digital elements are to be overlayed,

(2) Listening to the adhan/call to prayer that signifies the time for prayer and initiates the mental preparation for worship

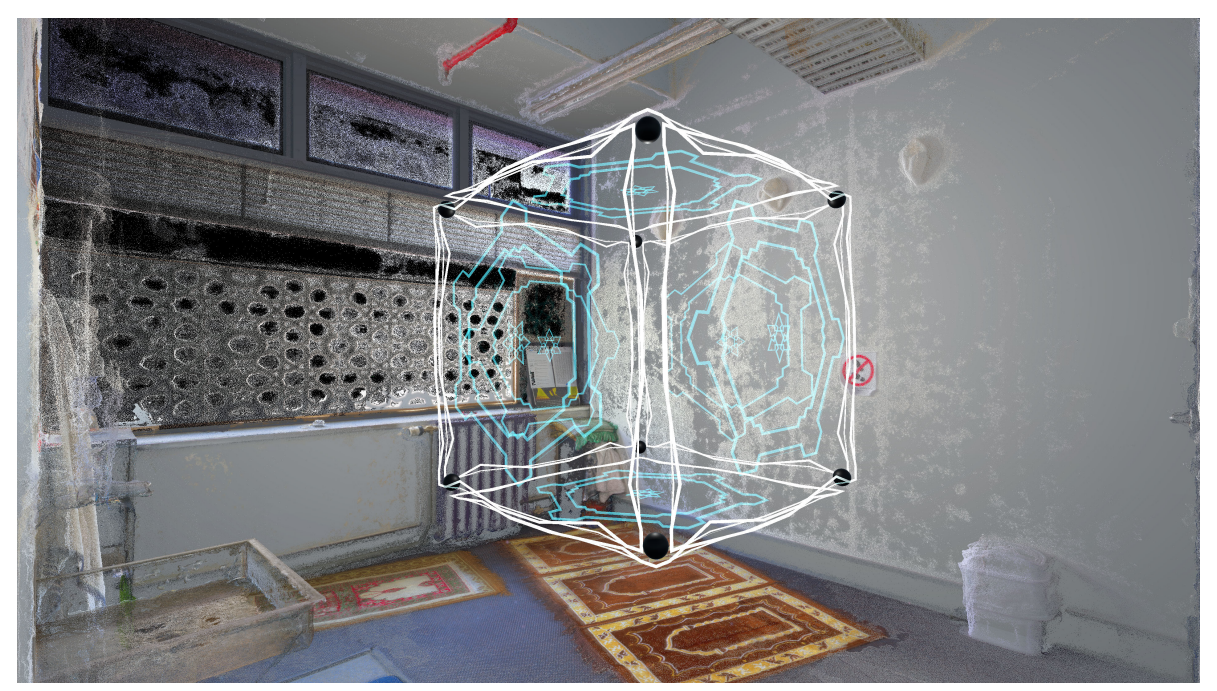

Figure 1. Key Event 2 -Visual Adhan/Call to prayer (Augmented Reality).

(3) Performing Virtual Tayammum - cleansing of the mind and body prior to worship, 


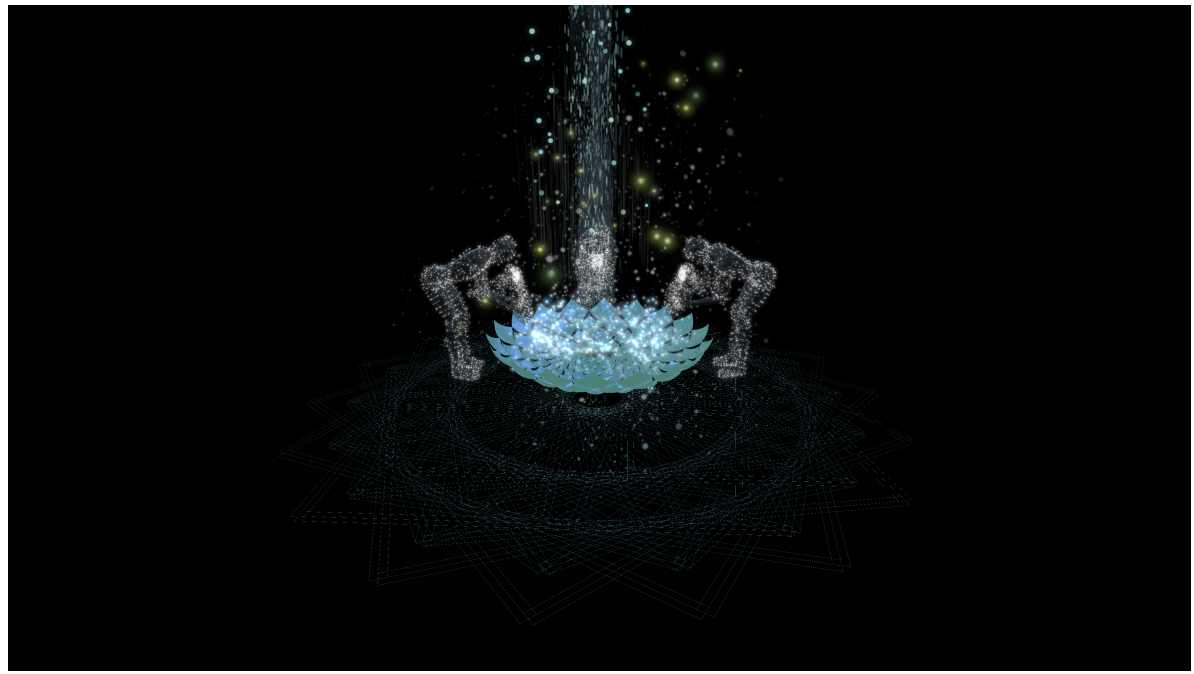

Figure 2. Key Event 3 - Virtual Tayammum(Augmented-Virtuality).

(4) Performing Salah/prayer - the act of worship.

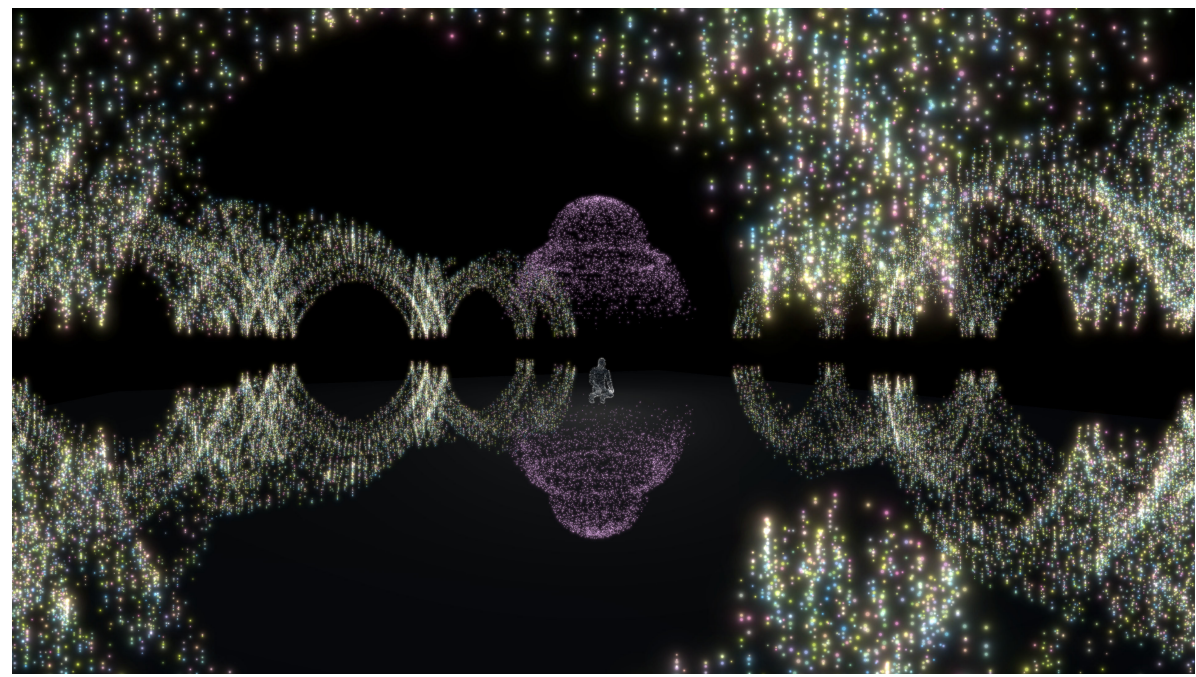

Figure 3. Key Event 4 - Digital Mosque (towards Virtual Reality).

\section{Conclusion}

Through this body of creative works, my research identifies:

- How a synthesis of space and cultural information can provide impactful, poetic and deep immersion. 
- How methodology can evolve and incorporate theories and technologies of mixed reality within traditional architectural frameworks.

- How the development of an Adaptive Multifaith Space can blend the physical and digital in order to create an inclusive space for all.

The development of the immersive experience intends to highlight how the merger of the virtual with the real can enhance our experience of the built environment. The phenomenological impact of this merger is significant but it goes further by engaging intuitive concepts related to society and culture. Throughout history, architecture has symbolically been used to dominate and dictate, divide and isolate various communities and individuals; Yet with every passing day, it has also been used to provide freedom and opportunity, unite and strengthen those very same persons. This immersive experience aims to represent religion and customs through the lens of contemporary culture that is widely connected and continually evolving.

The experience aims to act as a catalyst that pushes for engagement and discussion on the future of religion within society. By interpreting the rituals and customs of our varying faiths, we are creating an opportunity for many to experience religious practices through the eyes of others. An interpretation is different from depiction; interpretations help to remove any preconceived notions that we may have of religion and those who practice. In the process, we learn to respect and appreciate the diverseness of our shared existence.

\section{References}

Anders, P.A.: 2005, Cybrid Principles: Guidelines for Merging Physical and Cyber Spaces, International Journal of Architectural Computing, 3(3), 391-406.

Anders, P.A.: 2007, Designing Mixed Reality: Perception, Projects and Practice, Proceedings of the 27th Annual Conference of the Association for Computer Aided Design in Architecture, 276-283.

Crompton, A.C.: 2013, The Architecture of Multifaith Spaces: God Leaves the Building, Journal of Architecture, 18(4), 474-496.

Duddumpudi, K.D., Moloney, J.M. and Moleta, T.J.M.: 2003, Whispering Walls, Proceedings of the 31st eCAADe Conference - Volume 1, 507-516.

Imdat, A.I.: 2006, The Digital Mosque, Journal of Architectural Education, 60(1), 54-66.

Longhurst, C.L. 2016, Western Mosque and Muslim Integration: Identity Crisis and Resolution, in E.K. Kolig (ed.), Muslim Integration: Pluralism and Multiculturalism in New Zealand and Australia, Lexington Books.

Manovich, L.M.: 2006, The Poetics of Augmented Space, Visual Communication, 5(2), 219-240.

Qureshi, C.Q., Schnabel, M.A.S. and Moleta, T.J.M.: 2018, CityAR:Wellington Exploring Cities through Mixed Realities, Proceedings of the 36th eCAADe Conference - Volume 2, 687-692.

Schnabel, M.A.S. 2009, Framing Mixed Realities, in M.A.S. Schnabel and X.W. Wang (eds.), Mixed Reality In Architecture, Design, And Construction, Springer, 3-11. 